\title{
INVESTIGATION OF METALLIC SURFACE AREA OF CORONARY STENTS
}

Dóra Károly ${ }^{1}$, Miksa Kovács ${ }^{1}$, Andrew Attila Terdik ${ }^{1}$, Eszter Bognár ${ }^{1,2}$

${ }^{1}$ Department of Materials Science and Engineering, Faculty of Mechanical Engineering, Budapest

University of Technology and Economics

${ }^{2}$ MTA-BME Research Group for Composite Science and Technology

karoly.dora@gmail.com

\begin{abstract}
OBJECTIVES: Endovascular stents, such as coronary stents, are widely used for the treatment of narrowed or blocked blood vessels caused by plaque formation in the arteries. The narrowing of expanded blood vessels (restenosis) is perhaps the major complication associated with endovascular stent implantation that is believed to be caused by insufficient metallic surface area (MSA) in some stent designs. Our aim was to compare three examination methods which were developed at our department, to measure stent surface areas.

METHODS: The first method was manually performed using rotating equipment under a stereomicroscope. The second method, which has recently been developed, is an automated method using an integrated scanner and a rotating engine. Both methods aimed at converting the cylindrical stent into a flattened two-dimensional image in order to enable the measurement of stent surface area by imaging software. The third method is based on a calculation which uses various stent values such as diameter, length, and strut thickness. Each measurement process was tested on different types of stents.
\end{abstract}

RESULTS: Our findings showed that the methods gave similar results. The largest differences between the methods were speed and accuracy.

CONCLUSIONS: The results lead us to propose favouring the automated rotation method.

Keywords: coronary stent, metallic surface area (MSA), stent pattern, cell size, examination method

\section{Introduction}

In the European Union the commonest reason of death is diseases of the cardiovascular system, amongst which the most significant is coronary artery disease. The numbers are still increasing, so preventing this disease is a high priority in public health policy. ${ }^{1}$

Stent implantation is the primary method of angioplasty to treat atherosclerosis. A stent is a small mesh tube structure mounted on a balloon and delivered to the site of arterial narrowing by a catheter system. When the balloon is inflated, pressure expands the stent and causes its deformation plastically. After the deflation of the balloon and the removal of the catheter system, the newly expanded stent rigidly supports the arterial wall, alleviating the arterial narrowing. Therefore the artery is reopened to its full extent and blood flow to downstream tissues restored. ${ }^{2}$ We prepared the following explanatory 3D models (Figure 1). 

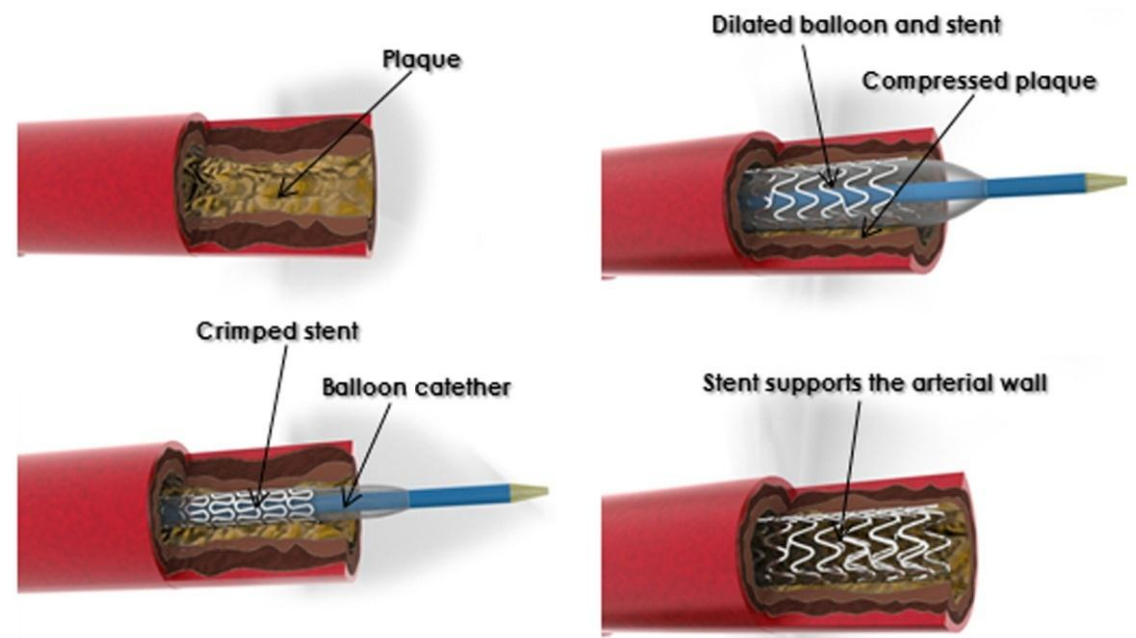

Figure 1. Stent dilating process

The narrowing of expanded blood vessels (restenosis) is perhaps the major complication associated with endovascular stent implantation. It is believed to be caused by inadequate MSA in stents. ${ }^{3}$ The metallic surface area (MSA) of coronary stents is a ratio given as a percentage, of the stent's cylindrical surface to the covered surface of the blood vessel. For technical reasons too high a ratio is not recommended, because the contact area with the blood vessel wall is too large. In this case the risk of thrombus formation increases, increasing the risk of restenosis. On the other hand, too small a ratio can lead to mechanical problems. ${ }^{4}$

$30-35 \%$ of all percutaneous coronary interventions involve small-diameter vessels of less than 3 $\mathrm{mm}$. Small blood vessel size correlates with risk of restenosis after balloon angioplasty, as well as after stent placement. Stents deployed in small arteries have a higher metal-to-artery ratio; this may increase the risk of sub-acute thrombosis or restenosis. Various studies have shown that stent design, stent coating, and stent strut thickness may all influence event-free survival. Dedicated stents for small vessels with less metal (so a smaller metallic surface area), appropriate expansion properties and cell morphology, may further improve the results from stenting in this setting. ${ }^{5}$

Most studies related to stent surface focus on stent coatings. They are looking for a material, that meets mechanical requirements and generates an optimal biological response in the body. Because of this, knowing the exact size and geometry of the stent surface is very important. Furthermore, in the case of drug-eluting stents the stent pattern can also affect uniform dissolution.

In our work we looked at two experimental methods and a calculation to determine the MSA value and we compared their efficiency. All methods were developed at our department.

\section{Methods and materials}

In the study we investigated 4 coronary stents. (A) stent (Figure 2) and (B) stent (Figure 3) have the same geometry, but different size. (C1) stent (Figure 4) and (C2) stent (Figure 5) have the same geometry and size too. The stents were expanded at nominal pressure. The experimental methods are shown by the $3.0 \times 8 \mathrm{~mm}, \mathrm{~L} 605 \mathrm{CoCr}$ (A) stent. 


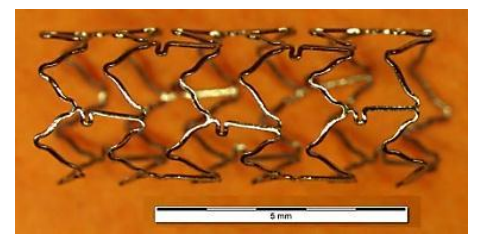

Figure 2. $3.0 \times 8 \mathrm{~mm}$ stent $(\mathrm{A})$

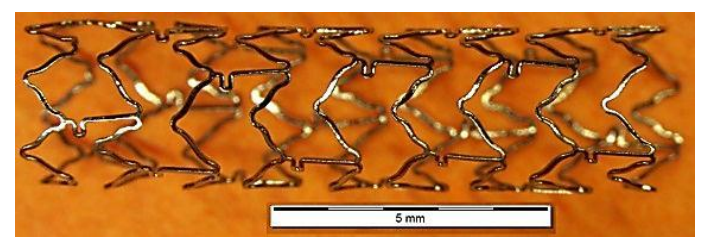

Figure 3. $3.0 \times 12 \mathrm{~mm}$ stent (B)

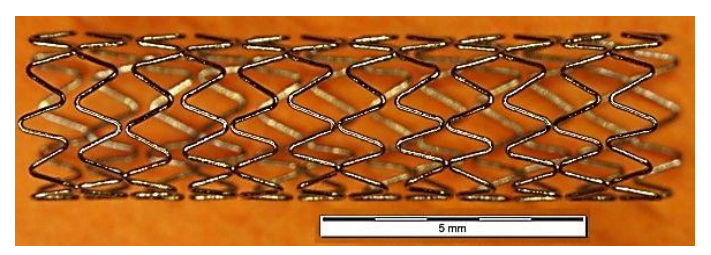

Figure 4. $3.0 \times 12 \mathrm{~mm}$ stent (C1)

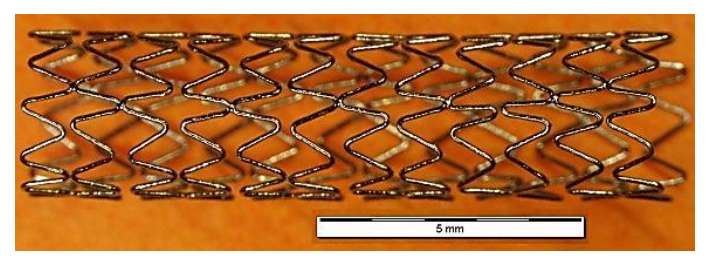

Figure 5. $3.0 \times 12 \mathrm{~mm}$ stent (C2)

\begin{tabular}{|c|c|c|c|c|c|c|c|}
\hline $\begin{array}{c}\text { Stent } \\
\text { name }\end{array}$ & $\begin{array}{c}\text { Diameter } \\
{[\mathbf{m m}]}\end{array}$ & $\begin{array}{c}\text { Length } \\
{[\mathbf{m m}]}\end{array}$ & $\begin{array}{c}\text { Mass } \\
{[\mathbf{m g}]}\end{array}$ & $\begin{array}{c}\text { Density } \\
{\left[\mathbf{g} / \mathbf{c m}^{\mathbf{3}}\right]}\end{array}$ & $\begin{array}{c}\text { Strut } \\
\text { thickness } \\
{[\mathbf{m m}]}\end{array}$ & $\begin{array}{c}\text { Nominal } \\
\text { pressure } \\
{[\mathbf{1 0} \mathbf{5} \mathbf{~ P a}]}\end{array}$ & Material \\
\hline (A) & 3.0 & 8 & 9.5 & 9.1 & 0.085 & 9 & $\mathrm{CoCr}(\mathrm{L} 605)$ \\
\hline (B) & 3.0 & 12 & 11.2 & 9.1 & 0.085 & 9 & $\mathrm{CoCr}(\mathrm{L} 605)$ \\
\hline (C1) & 3.0 & 12 & 17.7 & 9.1 & 0.091 & 9 & $\mathrm{CoCr}(\mathrm{L} 605)$ \\
\hline (C2) & 3.0 & 12 & 17.7 & 9.1 & 0.091 & 9 & $\mathrm{CoCr}(\mathrm{L} 605)$ \\
\hline
\end{tabular}

Table 1. Data for the investigated stents

Table 1 shows the investigated stent systems' basic dimensions. Investigations were performed by stereo microscopy and a scanner. Surface areas were determined by evaluating the digital images with image analysis software. Evaluation was performed with JMicroVision measuring software. All measurements correspond to the MSZ EN ISO 25539-2 standard. ${ }^{6}$ 


\subsection{The manual method}

The first method was performed by manual stereo-microscopy. High-resolution digital images were taken of each segment of the stents' mantle. The pictures were taken with a stereo microscope fitted to a precision rotary unit. The stents were rotated by increments of $15^{\circ}$ from the starting $0^{\circ}$ position to $360^{\circ}$. The 24 pictures were then joined to each other, and examined with image analysis software.

\subsection{The automatic method}

The second method was done in an automated manner by a new configuration. The stents were pulled up to a shaft connected to a motor, so that the stents were rotating during the scanning process. In this case we get one whole picture of the stent pattern. The rotational speed and direction can be changed using the buttons of the control panel. Pictures were taken at a resolution of 4800 DPI. The Canon CanoScan LiDE 700F scanner that we used has a 9600 DPI resolution, so the images have far better quality than required.

Both (the first and the second) methods aimed at converting the cylindrical stent into a flattened 2 dimensional image in order to analyse the stent pattern with imaging software. With the stent pattern, the largest and the smallest cell area, and the maximum achievable cell diameter in them can be easily determined by an image analysis program. This feature is useful when another stent needs to be placed into a side branch of a vessel and the physician has to go through one of the stent cells with another stent or a balloon catheter.

\subsection{The calculation}

The third method is based on a calculation using various stent values such as stent diameter, length and strut thickness. If we imagine an ideal tube where we know the material (and thus density of the material), and set the outer diameter, length and wall thickness to be the same as the stent's, then by defining these features we can calculate the mass of the ideal tube which would have a 100\% MSA value. We use the following formula (Equation 1):

$$
\mathrm{m}_{\text {tube }} \approx \mathrm{d} \cdot \pi \cdot \mathrm{l} \cdot \mathrm{s} \cdot \rho
$$

where mtube: mass of the tube, d: stent outer diameter, l: stent length, s: tube's wall thickness (so the strut thickness of the stent), @: density of the stent.

We get the metallic surface area (MSA) from the ratio of the stent mass (mstent) and the calculated mass of the ideal tube which has 100\% MSA value (Equation 2).

$$
\mathrm{MSA}=\frac{\mathrm{m}_{\text {stent }}}{\mathrm{m}_{\text {tube }}} \cdot 100[\%]
$$


To determine the strut thickness a slide was made from a normal (perpendicular) section of the struts. Given a large number of test samples, this significantly complicates the measurements. Also, this calculation only gives information about the MSA value and nothing about cell sizes.

\section{Results}

Our findings showed that the first and the second methods gave similar results (Figure O). The third method gave a different MSA value for the (B), (C1) and (C2) stents. These are early estimates, but further studies will explore possible reasons for the difference.

The location of the largest and smallest cells are the same with the manual and the automatic method, except in the case of (C1) stent, where the location of the largest cell was different. Since the difference between the largest and the second largest cell was negligibly small, the error might be due to inappropriate joining of images.

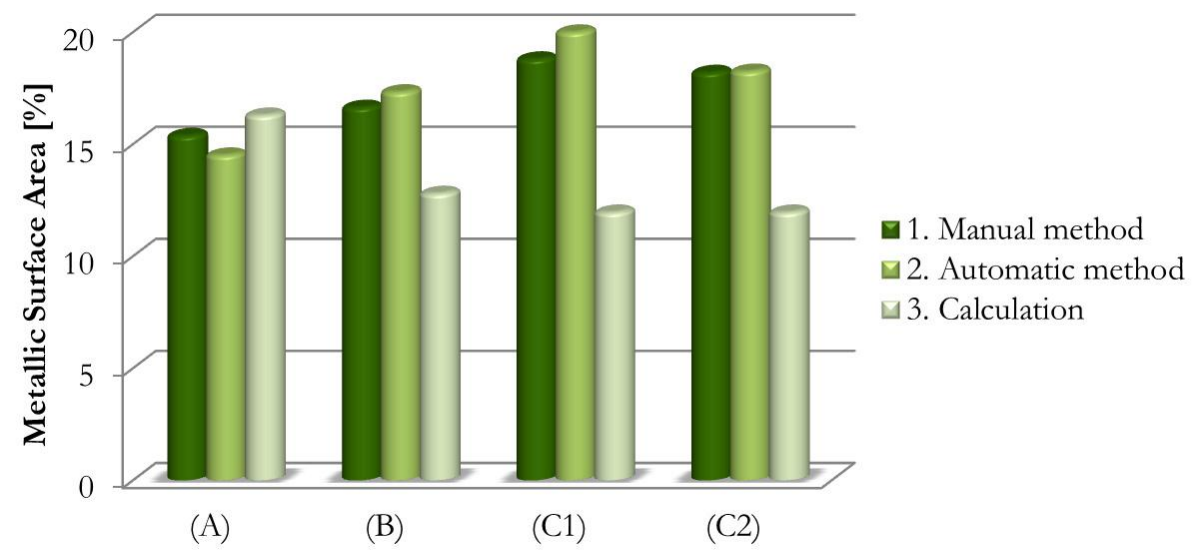

Figure 6. MSA values with the three methods

Figure 7 shows the stent pattern of stent (A) with the manual and the automatic method. The largest cell is yellow, the smallest cell is blue, and the circles with the maximum achievable diameter are red. Each stents' cells were counted; (A) has 12 cells, (B) has 15 cells, (C1) and (C2) both have 24 cells.

(a)

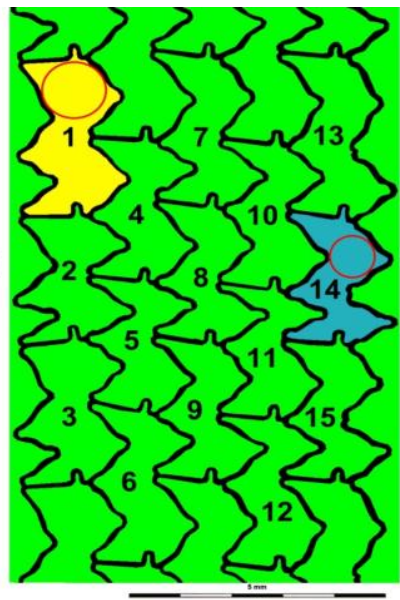

(b)

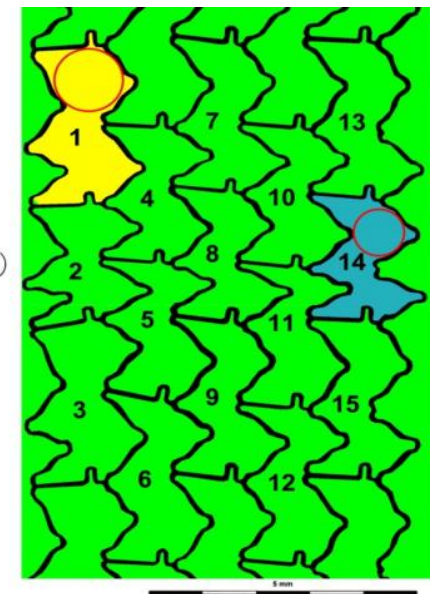

Figure 7. The evaluated stent pattern of stent (A)

(a) with the manual method (b) with the automatic method 
The metallic surface areas of all these stents are maximum $20 \%$. This is appropriate for the reformation of the intima cell layer. The measurement results are given with the following markings (Table 2):

- largest cell area (marked in yellow in Figure 7): ALC $\left[\mathrm{mm}^{2}\right]$

- maximum diameter of the circle in the largest cell (marked in red in Figure 7): DLC [mm]

- smallest cell area (marked in blue in Figure 7): ASC $\left[\mathrm{mm}^{2}\right]$

- maximum diameter of the circle in the smallest cell (marked in red in Figure 7): DSC [mm]

- average cell area: AAC $\left[\mathrm{mm}^{2}\right]$

\begin{tabular}{|c|c|c|c|c|c|c|c|}
\hline Stent & Method & $\begin{array}{c}\text { MSA } \\
{[\%]}\end{array}$ & $\begin{array}{c}\mathbf{A}_{\mathrm{LC}} \\
{\left[\mathrm{mm}^{2}\right]}\end{array}$ & $\begin{array}{c}\mathbf{A s C}_{\mathrm{sC}} \\
{\left[\mathrm{mm}^{2}\right]}\end{array}$ & $\begin{array}{c}\mathbf{A}_{\mathbf{A}} \\
{\left[\mathrm{mm}^{2}\right]}\end{array}$ & $\begin{array}{c}\mathbf{D}_{\mathrm{LC}} \\
{[\mathrm{mm}]}\end{array}$ & $\begin{array}{c}\mathbf{D}_{\mathrm{sC}} \\
{[\mathrm{mm}]}\end{array}$ \\
\hline \multirow[t]{3}{*}{ (A) } & 1. Man. & 15.38 & 4.12 & 2.72 & 3.33 & 1.25 & 0.89 \\
\hline & 2. Auto. & 14.51 & 4.03 & 2.70 & 3.31 & 1.25 & 0.91 \\
\hline & 3. $\mathrm{Cal}$ & 16.29 & & & & & \\
\hline \multirow[t]{3}{*}{ (B) } & 1. Man. & 16.64 & 3.58 & 2.41 & 2.99 & 1.08 & 0.93 \\
\hline & 2. Auto. & 17.33 & 3.62 & 2.22 & 2.94 & 1.07 & 0.89 \\
\hline & 3. Cal & 12.80 & & & & & \\
\hline \multirow[t]{3}{*}{ (C1) } & 1. Man. & 18.80 & 3.88 & 1.61 & 3.14 & 0.83 & 0.68 \\
\hline & 2. Auto. & 20.32 & 3.88 & 1.77 & 3.26 & 0.86 & 0.71 \\
\hline & 3. Cal & 11.96 & & & & & \\
\hline \multirow[t]{3}{*}{$(\mathrm{C} 2)$} & 1. Man. & 18.20 & 4.06 & 1.70 & 3.19 & 0.81 & 0.68 \\
\hline & 2. Auto. & 18.25 & 4.04 & 1.79 & 3.25 & 0.81 & 0.69 \\
\hline & 3. Cal & 11.96 & & & & & \\
\hline
\end{tabular}

Table 2. The measurement results

\section{Discussion}

The largest differences between the methods were speed and accuracy. Calculation was the quickest, but it gives just estimated results without cell sizes. Further studies will be taken to explore the accuracy of this method.
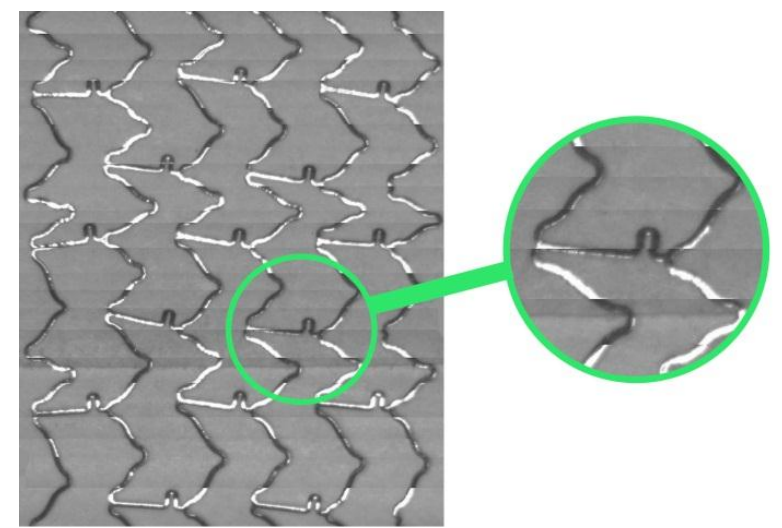

Figure 8. Stent (A) pattern with the manual method 
The automatic method also needs less time (the difference is in hours), because the pictures did not need to be joined together. This is an important factor when the stent is too long to fit in the microscopic field. In that case separate images are taken of both ends of the stent, and then 48 images have to be joined up to create one big image. Resulting errors are multiplied during image editing, and time needed also increases.

In addition, Figure 8 clearly shows that the struts reflect light in the microscope pictures of the metal stent surface. Bright and dark parts seem to have different strut widths which need to be corrected during evaluation. This both takes more time and causes inaccuracy. In contrast, reflective glare is eliminated in the images taken by scanner (Figure 9).

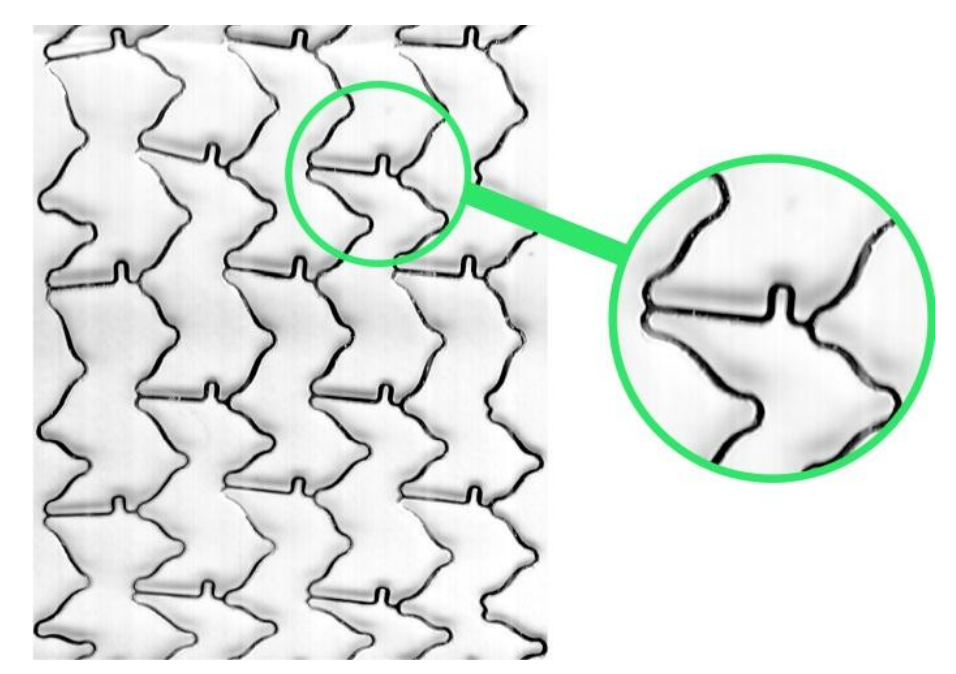

Figure 9. Stent (A) pattern with the automatic method

\section{Conclusion}

Some stent properties are important during implantation such as crossing profile or flexibility of the stent system, and others are important for the long-term effectiveness of the stent after implantation such as metallic surface area, the largest and the smallest cell sizes, and the maximum achievable cell diameter.

We used 3 methods to measure MSA values. These results favour the automatic method, which on the basis of this study seems to give the most information, most accurately, in the shortest time. The collected experience and results of this study provide a basis for further research. We plan to use the obtained image data to create a three-dimensional stent model and run finiteelement simulations to predict mechanical properties of stents with given defined patterns. 


\section{REFERENCES}

1. Bertrand OF, et al, Biocompatibility Aspects of New Stent Technology. J Am Coll Cardiol, 1998;32: $562-71$.

2. Ning L, Yuanxian G. Parametric Design Analysis and Shape Optimization of Coronary Arteries Stent Structure. 6th World Congresses of Structural and Multidisciplinary Optimization, Rio de Janeiro, 2005 May 30 - June 3.

3. Takács T, Bognár E, Dobránszky J. Az újraszúkülést befolyásoló paraméterek vizsgálata coronariastenteken. LAM 2010;20(3-4):227-233.

4. Ring Gy. Koszorúérsztentek és más endoprotézisek preklinikai vizsgálata. BME GPK PhD dissertation. Budapest, 2010.

5. Roguin A, Grenadier E. Stent-based percutaneous coronary interventions in small coronary arteries. Acute Card Care, 2006;8(2):70-4.

6. MSZ EN ISO 25539-2:2009 Cardiovascular implants. Endovascular devices. Part 2: Vascular stents (ISO 25539-2:2008)

First we would like to thank János Dobránszky for valuable advice. Further we would like to thank the Department of Materials Science and Engineering and colleagues there for providing us with the environment and facilities to complete this project. Also, we would like to take this opportunity to thank Vascular Venture Ltd. for providing us with stents. This work is connected to the scientific program of the "Development of quality-oriented and harmonized $R+D+I$ strategy and functional model at BME" project. This project is supported by the New Hungary Development Plan (Project ID: TÁMOP-4.2.1/B09/1/KMR-2010-0002). 